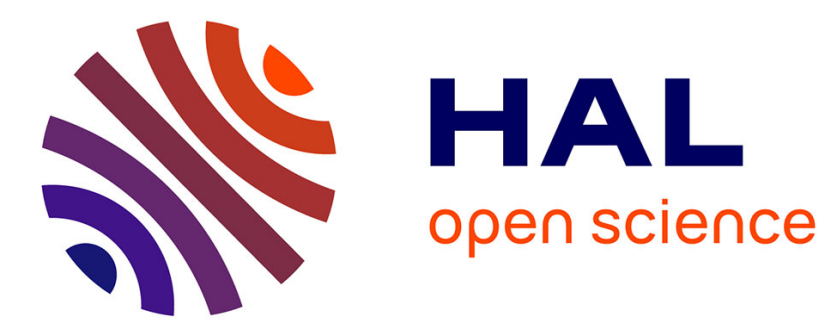

\title{
Loss of REM sleep features across nighttime in REM sleep behavior disorder
}

Dario Arnaldi, Alice Latimier, Smaranda Leu-Semenescu, Marie Vidailhet, Isabelle Arnulf

\section{> To cite this version:}

Dario Arnaldi, Alice Latimier, Smaranda Leu-Semenescu, Marie Vidailhet, Isabelle Arnulf. Loss of REM sleep features across nighttime in REM sleep behavior disorder. Sleep Medicine, 2016, 17, pp.134-137. 10.1016/j.sleep.2015.10.019 . hal-01292432

\section{HAL Id: hal-01292432 https://hal.sorbonne-universite.fr/hal-01292432}

Submitted on 29 Mar 2016

HAL is a multi-disciplinary open access archive for the deposit and dissemination of scientific research documents, whether they are published or not. The documents may come from teaching and research institutions in France or abroad, or from public or private research centers.
L'archive ouverte pluridisciplinaire HAL, est destinée au dépôt et à la diffusion de documents scientifiques de niveau recherche, publiés ou non, émanant des établissements d'enseignement et de recherche français ou étrangers, des laboratoires publics ou privés. 


\section{Loss of REM sleep features across nighttime in REM sleep behavior disorder}

Dario Arnaldi, ${ }^{1,2}$ Alice Latimier, ${ }^{3}$ Smaranda Leu-Semenescu, ${ }^{1,3}$ Marie Vidailhet, ${ }^{3,4}$ Isabelle Arnulf ${ }^{1,3}$

1- APHP- Pitié-Salpêtrière Hospital, Sleep disorders unit, Paris, France

2- Clinical Neurology, Dept. of Neuroscience (DINOGMI), University of Genoa, Italy

3- Brain Research Institute- UPMC Paris 6 Univ, Inserm U 1127; CNRS UMR 7225, Paris, France

4- APHP- Pitié-Salpêtrière Hospital, Neurology Department, Paris, France

Word count: 1415

Abstract : 247

References : 20

Corresponding author: Isabelle Arnulf,

Service des pathologies du sommeil

Hôpital Pitié-Salpêtrière

47-83 boulevard de l'Hôpital

75651 Paris cedex 13, France

E-mail: isabelle.arnulf@psl.aphp.fr

Phone: 33142167702

Fax: 33142167700

\section{Funding}

The work was supported by Agence Nationale de la Recherche (ANRMNP 2009, Nucleipark),

DHOS-Inserm (2010, Nucleipark), France Parkinson (2008) and IHU de neurosciences. 


\begin{abstract}
Background. Melatonin is a chronobiotic effective in the treatment $\theta$ fwhich also alleviates REM sleep behavior disorder (RBD). Because the mechanisms of this benefit are unclear, we evaluated the clock-dependent REM sleep characteristics in patients with RBD, whether idiopathic (iRBD) or associated with Parkinson Disease (PD), and we compared findings with PD patients without RBD and with healthy subjects.
\end{abstract}

Methods. An overnight videopolysomnography was performed in 10 iRBD patients, 10 PD patients with RBD (PD+RBD+), 10 PD patients without RBD (PD+RBD-) and 10 healthy controls. The rapid eyes movements frequency per minute (REMs index), the tonic and phasic EMG activity of the levator menti muscle and the REM sleep duration of each REM sleep episode were evaluated. A generalized linear model was applied in each group, with the REM sleep cycle (four ordinal levels) as the dependent variable, as function of REMs index, REM sleep duration and tonic and phasic EMG activity.

Results. From the first to the fourth sleep cycle, REM sleep duration progressively increased in controls only, REMs index increased through the sleep cycles-in subjects without RBD (i.e. controls and PD+RBD- patients) but not in patients with RBD, whether idiopathic or associated with PDREM sleep duration increased from the first to the last sleep cycle in controls., whereas tFonic and phasic EMG activity did not change-with REM sleep cycles.

Conclusions. Patients with PD or iRBD lost the physiologic circadian increase in REM sleep duration, and pPatients with RBD (either with or without PD) lost the circadian increase of REMs frequency across the night, suggesting an alteration in the circadian system $\underline{\text { in RBD. }}$. Thisit-_supports the hypothesis of a direct effect of melatonin on RBD symptoms by its chronobiotic activity.

Keywords: RBD; PD; melatonin; circadian 


\section{Introduction.}

Melatonin is an hormone secreted by the pineal gland mainly-involved in the endogenous synchronization of circadian rhythms ${ }_{-}{ }_{-}$- Exogenous melatonin is mainly used as a chronobiotic ${ }^{1}$ but is also effective in the treatment of REM sleep behavior disorder (RBD). ${ }^{2}$ In RBD patients, melatonin appears to both reduce clinical behavior and decrease muscle tone in REM sleep, ${ }^{2}$ but the mechanisms of this benefit are unclear. A direct effect of melatonin on RBD pathophysiology has been proposed, by potentiating gamma-aminobutyric acid (GABA)ergic inhibition, ${ }^{3}$ stabilizing circadian clock variability, ${ }^{4}$ and modulating the cytoskeletal structure through its antagonism of calmodulin. ${ }^{2}$ However, even if several REM sleep features depend on the functioning of the circadian timing system, ${ }^{5}$ the circadian, clock-dependent REM characteristics of RBD are still unknown.

The aim of the study was to evaluate the night, clock-dependent characteristics of REM sleep duration, the rapid eye movements (REMs) frequency and chin muscle tone during REM sleep in patients with RBD, whether idiopathic (iRBD) or associated with Parkinson Disease (PD), and to compare findings with both PD patients without RBD and with healthy subjects.

\section{Methods}

\subsection{Patients}

Thirty patients (iRBD, $n=10$, PD with RBD [PD+RBD+], $n=10$ and PD without RBD [PD+RBD-], $\mathrm{n}=10$ ) RBD were selected for the study. The PD and RBD diagnoses (including iRBD) followed current criteria. ${ }^{6,7}$ Main exclusion criteria were abnormal brain magnetic resonance imaging, neurological examination consistent with other neurological diseases, Mini-mental state examination (MMSE) less than 23 and the use of antidepressant, melatonin and benzodiazepine. The severity of parkinsonism was quantified using the Unified Parkinson's disease Rating Scale, part III (UPDRS-III) and the Hoehn and Yahr (H\&Y) stage. The levodopa-equivalent dose was computed in PD patients. Ten healthy volunteers in the same age range of the patients, without any 
neurological disorders and with normal imaging were recruited. All participants provided written informed consent. The studies (Nucleipark and Alice projects) were approved by the local ethics committee.

\subsection{Sleep monitoring}

All subjects underwent overnight videopolysomnography (vPSG) with sensors placed according to standard rules ${ }^{8}$ for scoring sleep, respiratory, cardiac, and limb events. Patients with RBD were asked to hold off melatonin at least 4 weeks before the PSG. Discrete REM sleep episodes had to be separated by a minimum of $15 \mathrm{~min}$, otherwise they were considered as a single REM sleep episode. The duration and the latency from the sleep onset of each subsequent REM sleep episode were measured. Eye movements were recorded by electro-oculograms (EOG), using a horizontal bipolar montage with a right mastoid reference. Eye movements during REM sleep (REMs) were selected if they had a duration shorter than $500 \mathrm{~ms}$ and an amplitude greater than $3^{\circ} .{ }^{9}$ REMs index corresponded to the number of REMs per minute of REM sleep and was calculated in each REM sleep episode. ${ }^{9}$ The electromyographic (EMG) recording of the levator menti muscle was monitored. In each subject, the tonic and phasic EMG activity was manually quantified during REM sleep, as performed by Frauscher et al. ${ }^{10}$

\subsection{Statistical analysis}

Since only 13 out of 40 subjects have shown five sleep cycles, only the first four cycles were analyzed. As a first step, the sleep-onset absolute time and REM sleep latencies for each cycle were compared between groups using univariate analysis of variance (ANOVA) to verify that REM sleep cycles were comparable between groups. To study the REM sleep cycle-specific sleep characteristics, a generalized linear model (GLM) was applied in each group, with the REM sleep cycle (four ordinal levels) as the dependent variable, as function of: i) REM sleep duration;; ii) REMs index ${ }_{2}^{;}$iii) tonic EMG activity; $;$; iv) phasic EMG activity. The sleep parameters were squareroot transformed to fit the assumption of identical, normal distribution. Pearson's correlation 
between both tonic and phasic EMG activity and REMs index were assessed. Total sleep cycle durations were compared among sleep cycles by repeated measures ANOVA. The demographic and sleep characteristics of the subjects were compared between groups using ANOVA (continuous measures) and chi-square test (categorical measures). The clinical characteristics of PD patients were compared by unpaired t-test. The normality assumption for ANOVA was checked by applying the Levene's test. A probability value lower than 0.05 was considered statistically significant. Statistical analysis was performed with Stata software (StataCorp. 2013, College Station, TX).

\section{Results}

The demographic, clinical and sleep finding between groups are summarized in Table 1. Sleeponset absolute time and REM sleep latencies were not different between groups, indicating that REM cycles have the same clock-dependency in each group. REM sleep duration progressively increased from the first to the fourth REM sleep cycle in controls (model coefficient $=0.38$; $p=0.036$ ) and only tended to increase in the other groups. REMs index increased through the sleep cycles in controls (model coefficient $=0.36 ; p=0.037$ ) and in PD+RBD- patients (model coefficient $=0.27 ; p=0.007$ ) but not in PD+RBD+ and iRBD patients. Tonic and phasic EMG activity did not change with REM sleep cycles. No significant correlations between REMs index and tonic or phasic EMG activity were found. Post-hoc Pearson's correlation between age and REMs index, performed to verify that the significant effect found in the GLM was not due to age, were not significant. Figure 1 and Supplemental Table A show tonic and phasic EMG activity, REM duration and REMs index over sleep cycles, by group. Sleep cycle durations were not different across cycles.

\section{Discussion}

The circadian, clock-dependent increase in REMs index that is seen in subjects without RBD (i.e., healthy subjects and PD patients without RBD) is absent in patients with RBD (whether idiopathic or associated with PD). The enhanced chin muscle tone (whether phasic or tonic) in REM sleep 
does not either follow a circadian pattern in these patients. Moreover, only healthy subjects (but not patients) have an increase in REM sleep duration through the sleep cycles.

Both timing and amount of REM sleep within the sleep cycles depend on the proper functioning of the circadian timing system. ${ }^{5}$ Usually, REM sleep amount increases over the course of a night sleep $^{11}$ (even in entrained conditions, as it is the case here) but, in our data, this only applies to healthy subjects, suggesting that PD or iRBD impact this usual profile. Patients with PD have reduced serum melatonin levels ${ }^{12}$ and peripheral clock gene expression ${ }^{13}$ compared with controls, suggesting an underlying alteration in the circadian system. Moreover, patients with PD have blunted circadian rhythm of melatonin secretion compared to controls, with reduction in both amplitude and 24-hours amount of melatonin secretion in semi-constant routine conditions. ${ }^{14}$ The circadian profile of melatonin secretion in iRBD is still unknown. However, iRBD is almost always a pre-motor stage of synucleinopathy, especially PD. ${ }^{15}$ Here, we have shown that both PD and iRBD patients have lost the circadian increase in REM sleep duration seen in healthy subjects. This could represent a sign of neurodegeneration, already present in iRBD. In addition, we have found that RBD (idiopathic or associated with PD), is characterized by a loss of the circadian increase of REMs over the night sleep. Since theis increase is intact in PD without RBD, this loss may be a marker of RBD rather than PD (Figure 1). REMs are usually present during 14-27\% of REM sleep time, with 5-35 REMs per minute. The REMs frequency normally increases from early to late REM sleep periods. ${ }^{16,17}$ The glutamatergic pontine and mesencephalic reticular formations are responsible for the REMs, but these structures are under the control of the cholinergic laterodorsal tegmental and pedunculopontine tegmental nuclei. ${ }^{18}$ In this model, the reciprocal interaction of REM-on cholinergic neurons and REM-off aminergic neurons determines the NREM-REM transitions over the sleep period. ${ }^{18}$ The cholinergic pedunculopontine nucleus is affected in PD. ${ }^{19}$ Plus, the cholinergic transmission may be selectively deficient in RBD (at least in PD), compared to the serotonergic and dopaminergic transmission. ${ }^{20}$ Thus, the loss of the circadian increase in REMs 
frequency in patients with RBD could represent an indirect marker of an altered circadian system, possibly involving the cholinergic neurons.

In conclusion, we found that patients with RBD and/or PD lost the circadian increase of REM sleep duration while patients with RBD (either with or without PD) lost the circadian increase of REMs frequency across the night. These findings suggest that an alteration in the circadian system is present in RBD patients. This is in line with the hypothesis of a direct effect of melatonin on RBD symptoms by its chronobiotic activity. It would be interesting to evaluate whether the circadian profile of melatonin secretion is blunted in patients with RBD and whether melatonin therapy restores the circadian aspect of REM sleep features in RBD patients. 
Table 1. Demographic, clinical and polysomnographic findings in healthy controls, patients with idiopathic REM sleep behavior disorder (iRBD) and patients with Parkinson's disease without (PD+RBD-) and with RBD (PD+RBD+).

\begin{tabular}{|c|c|c|c|c|c|}
\hline & Controls & iRBD & PD+RBD- & PD+RBD+ & $p$ value \\
\hline Number & 10 & 10 & 10 & 10 & \\
\hline Gender, male \% & 50 & 60 & 70 & 80 & n.s. \\
\hline Age, y & $61.0 \pm 7.0$ & $69.9 \pm 7.8^{\mathrm{a}}$ & $53.3 \pm 9.3$ & $62.3 \pm 7.9$ & $<0.001$ \\
\hline PD duration, $\mathrm{y}$ & NA & NA & $7.3 \pm 2.9$ & $9.8 \pm 3.7$ & n.s. \\
\hline L-dopa equivalent, $\mathrm{mg} / \mathrm{d}$ & NA & NA & $638 \pm 289$ & $773 \pm 277$ & n.s. \\
\hline Cognitive score, $0-30$ & $29.1 \pm 0.7$ & $29.0 \pm 1.3$ & $28.0 \pm 1.4$ & $28.1 \pm 1.4$ & n.s. \\
\hline UPDRS-III on score & NA & NA & $13.5 \pm 7.3$ & $19.1 \pm 6.2$ & n.s. \\
\hline UPDRS-III off score & $0.7 \pm 1.1$ & $2.1 \pm 2.3$ & $27.3 \pm 8.4$ & $33.9 \pm 9.4$ & n.s. \\
\hline Hoehn \&Yahr stage, 1-5 & 0 & 0 & $1.9 \pm 0.5$ & $2.0 \pm 0.8$ & n.s. \\
\hline \multicolumn{6}{|l|}{ Sleep measures } \\
\hline Total sleep time, min & $455 \pm 53^{\mathrm{a}}$ & $404 \pm 39$ & $399 \pm 59$ & $375 \pm 78$ & $<0.05$ \\
\hline Sleep efficiency, $\%$ & $88.9 \pm 4.8^{\mathrm{a}}$ & $76.8 \pm 8.6$ & $83.5 \pm 6.7$ & $76.6 \pm 7.9$ & $<0.001$ \\
\hline $\mathrm{N} 1, \%$ & $5.3 \pm 2.9$ & $7.2 \pm 7.2$ & $6.0 \pm 2.7$ & $7.8 \pm 4.4$ & n.s. \\
\hline $\mathrm{N} 2, \%$ & $46.6 \pm 5.2$ & $43.9 \pm 10.7^{\mathrm{a}}$ & $55.2 \pm 5.2$ & $54.5 \pm 8.4$ & $<0.01$ \\
\hline $\mathrm{N} 3, \%$ & $29.0 \pm 7.0$ & $26.4 \pm 12.7$ & $19.2 \pm 5.6$ & $15.4 \pm 8.1^{\mathrm{a}}$ & $<0.005$ \\
\hline Stage REM, \% & $19.2 \pm 4.3$ & $22.6 \pm 8.4$ & $18.9 \pm 8.9$ & $22.2 \pm 5.5$ & n.s. \\
\hline Tonic REM, \% & $1.6 \pm 1.5$ & $52.7 \pm 17.7^{\mathrm{a}}$ & $4.1 \pm 2.9$ & $22.9 \pm 14.6$ & $<0.0001$ \\
\hline Phasic REM, \% & $4.0 \pm 2.0$ & $33.6 \pm 8.6^{\mathrm{a}}$ & $5.9 \pm 6.0$ & $16.9 \pm 5.9$ & $<0.0001$ \\
\hline REMs index, $\mathrm{n} / \mathrm{min}$ & $7.9 \pm 13.5$ & $11.2 \pm 15.9$ & $6.5 \pm 5.8$ & $6.4 \pm 10.0$ & n.s \\
\hline Apnea-hypopnea/h & $10.1 \pm 10.0$ & $8.7 \pm 6.8$ & $10.4 \pm 14.1$ & $12.4 \pm 8.7$ & n.s. \\
\hline
\end{tabular}

${ }^{\mathrm{a} p}<0.05$ for post-hoc differences with other groups; UPDRS-III, Unified Parkinson's Disease Rating Scale, motor disability section. 
Supplemental Table A. REM sleep features for the first 4 sleep cycles. For each measure, the first line indicate mean values \pm standard deviations and the second line (in brackets) the relative withinpatients values, considering the first cycle being the $100 \%$.

\begin{tabular}{|c|c|c|c|c|}
\hline REM episode & $1^{\mathrm{rst}}$ & $2^{\text {nd }}$ & $3^{\text {rd }}$ & $4^{\text {th }}$ \\
\hline \multicolumn{5}{|l|}{ Controls } \\
\hline - Tonic REM, \% & $\begin{array}{c}0.35 \pm 1.1 \\
(100 \%)\end{array}$ & $\begin{array}{l}2.2 \pm 2.1 \\
(628 \%)\end{array}$ & $\begin{array}{l}2.6 \pm 5.2 \\
(753 \%)\end{array}$ & $\begin{array}{l}3.2 \pm 3.4 \\
(928 \%)\end{array}$ \\
\hline - Phasic REM, \% & $\begin{array}{l}2.4 \pm 1.2 \\
(100 \%)\end{array}$ & $\begin{array}{l}4.9 \pm 3.0 \\
(201 \%)\end{array}$ & $\begin{array}{l}4.5 \pm 3.3 \\
(190 \%)\end{array}$ & $\begin{array}{l}3.4 \pm 2.8 \\
(144 \%)\end{array}$ \\
\hline - REMs index, $\mathrm{n} / \mathrm{min}$ & $\begin{array}{l}2.6 \pm 2.9 \\
(100 \%)\end{array}$ & $\begin{array}{l}7.8 \pm 8.3 \\
(298 \%)\end{array}$ & $\begin{array}{l}5.1 \pm 4.9 \\
(193 \%)\end{array}$ & $\begin{array}{c}18.2 \pm 26.4 \\
(690 \%)\end{array}$ \\
\hline \multicolumn{5}{|l|}{ PD+RBD- } \\
\hline - Tonic REM, \% & $\begin{array}{l}4.3 \pm 9.2 \\
(100 \%)\end{array}$ & $\begin{array}{c}3.7 \pm 5.3 \\
(87 \%)\end{array}$ & $\begin{array}{l}6.2 \pm 8.2 \\
(138 \%)\end{array}$ & $\begin{array}{c}2.1 \pm 3.6 \\
(49 \%)\end{array}$ \\
\hline - Phasic REM, \% & $\begin{array}{l}4.8 \pm 4.9 \\
(100 \%)\end{array}$ & $\begin{array}{l}7.5 \pm 9.5 \\
(157 \%)\end{array}$ & $\begin{array}{l}6.5 \pm 4.9 \\
(137 \%)\end{array}$ & $\begin{array}{c}9.6 \pm 10.5 \\
(289 \%)\end{array}$ \\
\hline - REMs index, $\mathrm{n} / \mathrm{min}$ & $\begin{array}{l}3.1 \pm 2.6 \\
(100 \%)\end{array}$ & $\begin{array}{c}10.1 \pm 8.7 \\
(323 \%)\end{array}$ & $\begin{array}{c}9.1 \pm 10.9 \\
(289 \%)\end{array}$ & $\begin{array}{c}29.6 \pm 28.9 \\
(942 \%)\end{array}$ \\
\hline \multicolumn{5}{|l|}{ PD+RBD+ } \\
\hline - Tonic REM, \% & $\begin{array}{c}19.5 \pm 29.0 \\
(100 \%)\end{array}$ & $\begin{array}{c}23.1 \pm 15.0 \\
(119 \%)\end{array}$ & $\begin{array}{c}23.5 \pm 18.7 \\
(121 \%)\end{array}$ & $\begin{array}{c}20.5 \pm 10.6 \\
(105 \%)\end{array}$ \\
\hline - Phasic REM, \% & $\begin{array}{c}17.5 \pm 9.6 \\
(100 \%)\end{array}$ & $\begin{array}{c}18.4 \pm 9.0 \\
(105 \%)\end{array}$ & $\begin{array}{c}15.1 \pm 6.2 \\
(86 \%)\end{array}$ & $\begin{array}{c}16.0 \pm 5.8 \\
(91 \%)\end{array}$ \\
\hline - REMs index, n/min & $\begin{array}{l}3.1 \pm 1.7 \\
(100 \%)\end{array}$ & $\begin{array}{c}11.5 \pm 7.4 \\
(474 \%)\end{array}$ & $\begin{array}{l}3.9 \pm 3.8 \\
(126 \%)\end{array}$ & $\begin{array}{l}9.2 \pm 5.4 \\
(292 \%)\end{array}$ \\
\hline \multicolumn{5}{|l|}{ iRBD } \\
\hline - Tonic REM, \% & $\begin{array}{c}59.7 \pm 27.9 \\
(100 \%)\end{array}$ & $\begin{array}{c}57.0 \pm 22.9 \\
(96 \%)\end{array}$ & $\begin{array}{c}51.2 \pm 21.0 \\
(86 \%)\end{array}$ & $\begin{array}{c}64.3 \pm 23.7 \\
(108 \%)\end{array}$ \\
\hline - Phasic REM, \% & $\begin{array}{c}31.6 \pm 17.2 \\
(100 \%)\end{array}$ & $\begin{array}{c}38.0 \pm 12.3 \\
(120 \%)\end{array}$ & $\begin{array}{c}29.1 \pm 10.1 \\
(92 \%)\end{array}$ & $\begin{array}{c}41.6 \pm 17.6 \\
(132 \%)\end{array}$ \\
\hline - REMs index, n/min & $\begin{array}{l}2.6 \pm 1.5 \\
(100 \%)\end{array}$ & $\begin{array}{l}5.9 \pm 3.3 \\
(230 \%)\end{array}$ & $\begin{array}{l}4.8 \pm 5.9 \\
(185 \%)\end{array}$ & $\begin{array}{c}14.4 \pm 20.6 \\
(555 \%)\end{array}$ \\
\hline
\end{tabular}


Figure 1: Mean tonic and phasic EMG activity, REMs index and Tukey's boxplot of REM sleep duration over sleep cycle, by groups.
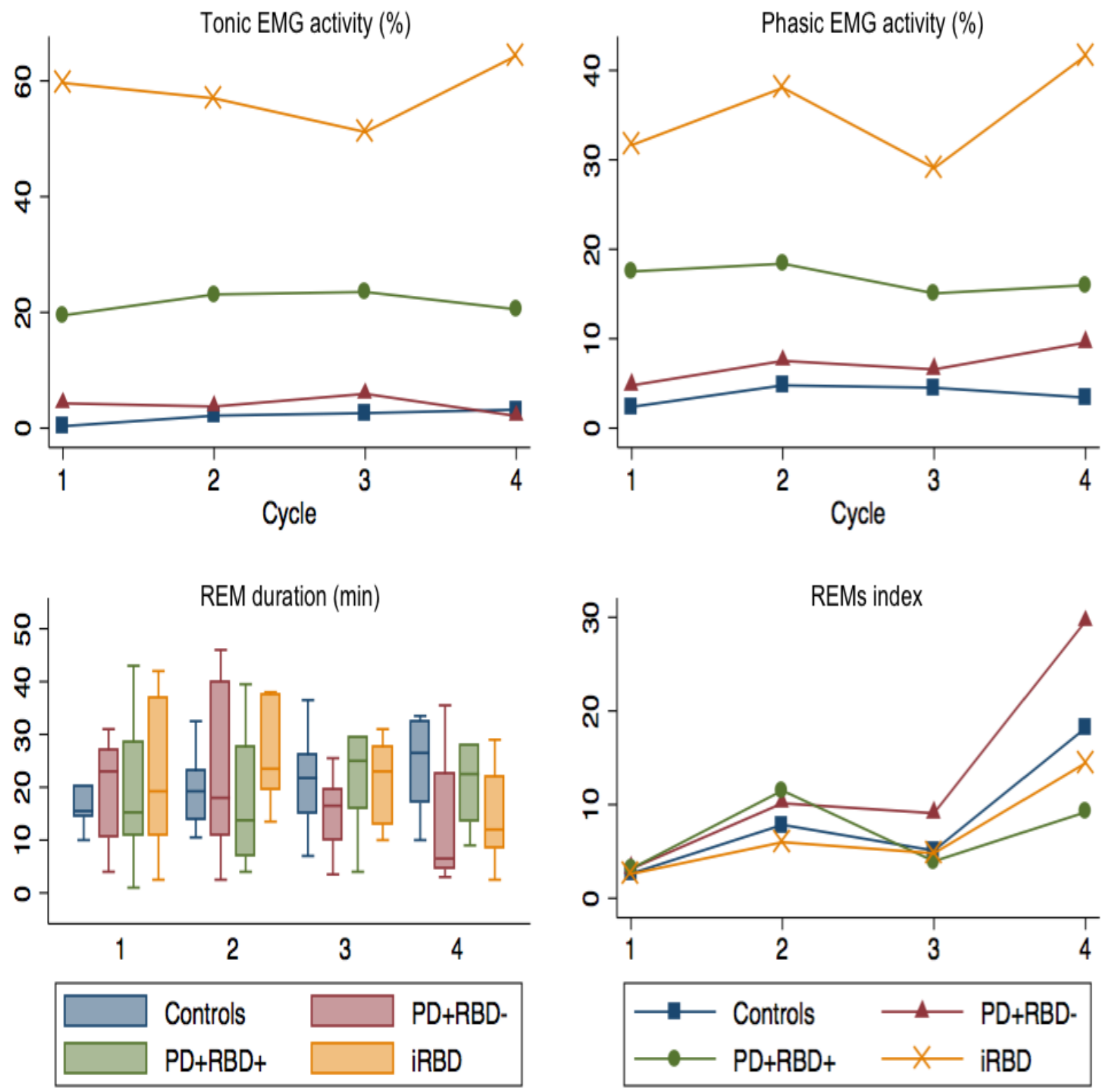


\section{References}

1. Arendt J, Skene DJ. Melatonin as a chronobiotic. Sleep Med Rev 2005;9(1):25-39.

2. McGrane IR, Leung JG, St Louis EK, Boeve BF. Melatonin therapy for REM sleep behavior disorder: a critical review of evidence. Sleep Med 2015;16(1):19-26.

3. Brooks PL, Peever JH. Impaired GABA and glycine transmission triggers cardinal features of rapid eye movement sleep behavior disorder in mice. J Neurosci 2011;31(19):7111-7121.

4. Kunz D, Bes F. Melatonin as a therapy in REM sleep behavior disorder patients: an openlabeled pilot study on the possible influence of melatonin on REM-sleep regulation. J Sleep Res 2010;19(4):591-6.

5. Wurts SW, Edgar DM. Circadian and homeostatic control of rapid eye movement (REM) sleep: promotion of REM tendency by the suprachiasmatic nucleus. J Neurosci 2000;20(11):43004310.

6. AASM. International Classification of Sleep Disorders - Second Edition (ICSD-2): diagnostic and coding manual. 2nd edition ed. Westchester (IL)2005.

7. Gelb DJ, Oliver E, Gilman S. Diagnostic criteria for Parkinson disease. Arch Neurol 1999;56(1):33-39.

8. Iber C, Ancoli-Israeli S, Chesson A, Quan SF. The AASM manual for the scoring of sleep and associated events: rules, terminology and technical specifications. . Westchester, IL: American Academy of Sleep Medicine, 2007.

9. Leclair-Visonneau L, Oudiette D, Gaymard B, Leu-Semenescu S, Arnulf I. Do the eyes scan dream images during rapid eye movement sleep? Evidence from the rapid eye movement sleep behaviour disorder model. Brain 2010;133(Pt 6):1737-1746.

10. Frauscher B, Iranzo A, Gaig C, et al. Normative EMG values during REM sleep for the diagnosis of REM sleep behavior disorder. Sleep 2012;35(6):835-847.

11. Brown RE, Basheer R, McKenna JT, Strecker RE, McCarley RW. Control of sleep and wakefulness. Physiol Rev 2012;92(3):1087-1187. 
12. Bordet R, Devos D, Brique S, et al. Study of circadian melatonin secretion pattern at different stages of Parkinson's disease. Clin Neuropharmacol 2003;26(2):65-72.

13. Cai Y, Liu S, Sothern RB, Xu S, Chan P. Expression of clock genes Per1 and Bmal1 in total leukocytes in health and Parkinson's disease. Eur J Neurol 2010;17(4):550-554.

14. Videnovic A, Noble C, Reid KJ, et al. Circadian melatonin rhythm and excessive daytime sleepiness in Parkinson disease. JAMA Neurol 2014;71(4):463-469.

15. Schenck CH, Boeve BF, Mahowald MW. Delayed emergence of a parkinsonian disorder or dementia in $81 \%$ of older men initially diagnosed with idiopathic rapid eye movement sleep behavior disorder: a 16-year update on a previously reported series. Sleep Med 2013;14(8):744-748. 16. Aserinsky E. Rapid eye movement density and pattern in the sleep of normal young adults. Psychophysiology 1971;8(3):361-375.

17. Takahashi K, Atsumi Y. Precise measurement of individual rapid eye movements in REM sleep of humans. Sleep 1997;20(9):743-752.

18. McCarley RW. Neurobiology of REM and NREM sleep. Sleep Med 2007;8(4):302-330.

19. Jellinger K. The pedunculopontine nucleus in Parkinson's disease, progressive supranuclear palsy and Alzheimer's disease. J Neurol Neurosurg Psychiatry 1988;51(4):540-543.

20. Kotagal V, Albin RL, Muller ML, et al. Symptoms of rapid eye movement sleep behavior disorder are associated with cholinergic denervation in Parkinson disease. Ann Neurol 2012;71(4):560-568. 